\title{
Mental Health Services Planning
}

\author{
Greg Wilkinson, Honorary Lecturer, Institute of Psychiatry, London SE5
}

A timely conference on Mental Health Services Planning. organized jointly by the Royal College of Psychiatrists and the Department of Health and Social Security, took place in London in March 1985.* The conference concentrated on difficulties associated with the implementation of government policies for mental health service planning in England and Wales. Particular emphasis was given to the problems of transition from hospital-based services to community-based services.

Of the large number of issues addressed at the meeting which were relevant to the implementation and development of policy in relation to psychiatric services, perhaps the fundamental one concerned the 'harmonization' of policies and priorities between central and local government, and between health and local authorities. The importance of continuity of management functions was also stressed, as was the need to ensure that scarce economic resources were used efficiently and effectively.

A persistent theme was highlighted by a Director of Nursing Services: despite the majority support for the devolution of services, general concern remained about the level of financing required since it was necessary to continue to provide existing services while developing new ones. He also raised the question of the role of the community psychiatric nurse in relation to the issue of the training and educational needs of staff working in the present services. These needs were said to be paramount if there was to be a successful move towards a different style of mental health service.

Detailed consideration was then given to the needs of three groups of patients in planning a community psychiatric service: short-stay patients, long-stay patients, and demented patients. From experience at Friern Hospital, one speaker concluded that whereas acute admission wards should be sited in the groups of district general hospitals, but in separately designed buildings, the care of long-stay and demented patients could be in non-hospital buildings. The central principle appeared to be that a district-based service should be founded on patients' needs.

A health-cconomic study from Lancashire indicated that the district general hospital psychiatric unit provided a good model on which to base psychiatric services. The author paid special attention to the role of the community psychiatric

- The proceedings of the conference will be published in due course. nurse in the treatment of patients with chronic psychotic disabilities in the community, and warned that as community psychiatric nurses drifted away from hospital-based services, one consequence might be that the care they currently gave to patients with chronic psychotic disorders would take second place to more unsupervised work with people with minor affective disorders. Other speakers argued that there would be a continuing need for the type of care currently provided in mental hospitals.

For psychiatrists with a responsibility for the care of the elderly, care in the community was said to be in existence already. However, this was sometimes difficult for them to justify, because many of their activities were 'invisible'-not being subject to routine data collection. The point was made that what the elderly received from services should be based on an assessment of their individual needs.

A significant factor beginning to emerge was that in some areas there were already more private sector nursing home beds than geriatric beds, and more private residential places than local authority places. This change in the provision of care for the elderly was underpinned by public funds, and it was urged that ways be found of integrating the private sector into the planning and implementation of mental health services for the elderly.

The gap existing between the principles and the practice of community care for the mentally handicapped continued to cause worry. In this regard, there was a call for more effective joint planning, the placing of mandatory responsibilities on Social Services Departments, and a substantial increase in funding for the development of services. It was recognized that new developments needed to be based on well-evaluated pilot projects rather than on the fashion and beliefs of the moment. For example, the principal of 'normalization' needed to be interpreted realistically. Generic services were not always appropriate: special facilities were likely to be needed for the mentally handicapped who become mentally ill and behaviourally disturbed elderly, and special arrangements needed to be made for aspects of their medical care.

The general theme emerged that the funding of community care should not be at the expense of hospital services, which were likely: (i) to provide residential care for the more resource intensive groups for some years ahead; and (ii) to be required for the development of specialized psychiatric facilities.

\section{New Journals}

Stress Medicine: This quarterly journal will aim to explore stress from as many aspects as possible: stress in the laboratory (basic research); stress in the community; psychology of stress; stresses in old age; stress and illness; assessment of stress: pharmacology of stress; and coping with stress. The Editor is Dr David Wheatley. Psychopharmacology Research Group. 325 Staines Road, Twickenham TW2 5AX. England.
Psychoanalytic Psychotherapy: This is the journal of The Association for Psychoanalytic Psychotherapy in the National Health Service and will be published three times a year. Any article of interest to psychoanalytic psychotherapists will be considered, including clinical case reports and theoretical papers. The Editor is Dr Michael Sinason, Psychoanalytic Psychotherapy, 3 Honeybourne Road, London NW6 1HH. 